\title{
Analysis on the Creative Application of Sports Game Strategy in the Physical Quality Exercises of College Students
}

\author{
Wanghaiyan ${ }^{1, *}$ \\ ${ }^{1}$ Sports Department of Nanjing Vocational College of Science and Technology, Nanjing, Jiangsu, China \\ a271640767@qq.com
}

\begin{abstract}
In the past, College Physical Education was relatively single and the content was boring. Integrating the links of sports games into the teaching can enliven the classroom atmosphere and promote students' interest in sports gradually, so as to improve the physical health level of vocational students and Physical Education teaching effect of physical quality.
\end{abstract}

Keywords: Physical Fitness, Sports Games, Strategy Analysis

\section{大学生身体素质练习中创新应用体育游戏策略分析}

\author{
王海燕 ${ }^{1, a}$
}

${ }^{1}$ 南京科技职业学院体育部，南京，江苏，中国

a271640767@qq.com

\section{摘要}

以往的大学体育身体素质练习相对单一, 内容枯燥, 在教学中融入体育游戏的环节可以活跃课堂气氛, 促进学生逐渐对体育运动产生兴趣, 从而提高大学学生体质健康水平和体育课身体素质教学效果。

关键词: 身体素质; 体育游戏; 策略分析

\section{1. 前言}

当前大学院校学生的体质健康水平仍是其综合素 质的明显短板。身体素质的如何直接反映人们在日常生 活中承受能力的强弱, 学生体体质状况下降势必影响学 生身体健康 ${ }^{[1]}$ 。身体素质练习作为大学体育课程中的重 要组成部分, 有效开展教学和练习对促进学生体质健康 有很重要的作用。目前在大学体育课的身体素质教学中, 普遍引进了体育游戏内容, 这种寓教于乐的形式提高了 大学生对体育活动的兴趣, 在身体素质练习上达到了传 统的教学模式所没有过的教学体验。

\section{2. 大学体育游戏教学的问题}

\section{1. 教学形式化}

大学体育教学中加入体育游戏的教学模式并不少 见, 但据调查很多大学开展的体育游戏教学都比较单调 枯燥。有的老师对于体育游戏理解为让学生自由活动, 放松了体育教学的环节, 没有进行系统的锻炼和运动,
也没有根据大纲开展体育教学活动, 因此造成了学生上 体育课只是尽情的玩游戏, 没有形成学习和锻炼机制, 影响了体育教学身体素质练习的效果 ${ }^{[2]}$ 。

\section{2. 针对性不足}

体育游戏有很多形式其中也不乏有项目针对性的 体育游戏, 由于体育游戏的多样性, 体育老师在选择的 时候带有一定的随意性 ${ }^{[3]}$, 没有根据体育项目的特点选 择有针对性的体育游戏, 因而不能对课堂教学产生促进 作用。体育游戏的强度和游戏的选择对于不同性别和身 体素质的学生来说会产生不一样的作用效果, 因此必须 对不同类项的学生选择合适的体育游戏, 让学生通过体 育游戏提高身体素质练习的效果。

\section{3. 缺乏趣味性}

身体素质练习中的体育游戏须具备趣味性, 来激发 学生对身体素质练习本身产生兴趣。通过体育游戏的互 动加强师生之间的联系, 还可以增进彼此的情感。但是 有的体育游戏缺乏趣味性, 学生在做游戏的时候觉得兴 致索然, 反而会缺乏参与感。而且有的体育游戏形式化 
明显因此也很难调动同学们的积极性。

\section{4. 忽视学生个体感受}

学生在做体育游戏的时候参与意识很强, 很多学生 为了团队的荣誉会尽力表现, 但是有的学生因为身体素 质的原因在游戏中表现得差强人意, 觉得给团队拖了后 腿, 所以对游戏产生了厌倦的情绪, 也对自己的体能产 生了怀疑, 造成不喜欢体育运的现象, 反会影响了体育 教学的开展。

\section{5. 内容枯燥}

游戏内容的选择需要与时俱进跟上时代的步伐, 有 的游戏形式过时, 内容单调枯燥, 学生不感兴趣, 参与 意识会下降。而且不同游戏内容本身的锻炼效果也不一 样, 过于单一的体育游戏内容不能对所有学生起到锻炼 的作用。

\section{6. 传统体育教学的影响}

以往的大学体育身体素质练习的教学内容比较枯 燥, 教学手段单一。老师只会让学生重复一些简单的动 作, 除了跑就是跳, 久而久之学生感受不到运动的乐趣, 也很难养成体育运动的兴趣, 老师没有从学生内心感受 的角度去关心学生。同一课堂中, 由于学生在性别和身 体素质上存在着差异, 课堂对学生不分彼此都采用一套 教学方法, 有的学生适应但是也有很多的学生不适应这 种教学方法, 因此可以通过开展体育游戏来辅助教学。

\section{3. 体育游戏在大学身体素质练习中的应用原 则}

\section{1. 安全性}

为了保证学生们可以安全的开展体育游戏必须要 确保游戏中不能存在安全隐患。为了防止意外发生, 可 通过设置合理的游戏规则规避运动风险。在游戏的过程 中, 老师需要在现场进行管控, 并且在运动场上配备必 要的应急救援的医疗箱, 一旦发生危险要马上进行施救, 立刻停止游戏对受伤的学生进行救治。

\section{2. 目的性}

体育游戏是身体素质练习的辅助教学形式, 在教学 中还是要以相应的身体素质教学为主。在挑选体育游戏 的时候要以服务于身体素质教学为目的, 选择可以提高 练习教学效果的体育游戏, 让同学们通过游戏潜移默化
的提高他们的身体素质水平 ${ }^{[3]}$ 。同时要结合身体素质五 个方面的特点, 采用有针对性提高身体素质的体育游戏。

\section{3. 趣味性}

体育游戏需要具有趣味性, 在给学生选择体 育游戏内容的时候, 要考虑在对应身体素质练习 的基础上增加练习的趣味性, 让学生们在游戏中 感受到运动带给他们的乐趣, 从而激发他们对练 习本身的兴趣。

\section{4. 竞争性}

体育游戏也要突出竞争的特点。体育运动魅力之一 就是因为它的竞技性, 所以竞技是体育运动的特点和乐 趣所在, 通过竞技可以激发人体的潜在能量提高体育运 动的水平。由于竞技运动的对抗性很强, 因此引导学生 开展体育游戏的时候, 要根据学生的身体素质的情况对 他们进行分组, 这样同等条件的学生在一起竞技会避免 由于身体素质问题, 引起有的学生由于没有参与的机会 而产生厌倦的情绪。

\section{5. 适度性}

游戏项目毕竟不同于真正的比赛, 因此在进行体育 游戏的时候, 不能过于追求竞技性还要以娱乐为主, 不 能由于竞技性太强失去了娱乐的意义, 要使体育游戏成 为一种寓教于乐的教辅手段。

\section{4. 大学身体素质教学中体育游戏创新策略}

在身体素质练习教学中学生通过体育游戏可以领 略体育运动的乐趣, 养成体育锻炼的习惯和体育爱好, 起到强身健体的作用。为了很好的发挥体育游戏的作用, 要从身体素质的五个方面有针对性地开展创新的体育 运动游戏。

\section{1. 力量练习中的体育游戏教学}

在大学体育课中身体素质练习力量方面衡量的指 标, 通常是采用引体向上、仰卧起坐和握力。传统教学 采用的方式也是简单直接的对这三个项目展开练习。由 于学生本身身体素质的局限性, 在练习的过程中往往无 法顺利进行。因此, 开展力量素质练习的体育游戏, 力 量素质要结合学生之间差异、性别差异、学生个体上下 肢力量的差异进行游戏内容的安排和分组。比如针对男 生引体向上, 有的男生上肢力量素质比较好, 直接上杆 练习对他的提高幅度有限。有些男生上肢力量素质较弱, 
直接上杆一个都拉不上, 打击其积极性。因此, 需要改 变练习的方式。采用搬运沙袋的游戏, 把男生的力量素 质按照强弱分组, 沙袋重量分类, 强者搬重的沙袋, 弱 者搬相对轻的沙袋。这样既能强弱、不同性别学生同时 进行游戏, 又能因人而异进行力量素质练习。除了这个 游戏适合力量素质练习的体育游戏还有很多, 都可以根 据具体的教学内容来开展。

\section{2. 速度、灵敏性素质练习的体育游戏教学}

速度是指在单位时间里完成动作的次数或是身体 快速位移的能力, 可以反映人体中枢神经系统的机能状 态和神经与肌肉的调节机能, 也可以综合地反映人体的 爆发力、灵敏、反应、柔韧等素质。其表现形式有反应 速度、动作速度和中期性运动中的位移速度。在大学体 育教学中, 测试指标有 50 米跑。对于绝大部分女生和 部分男生, 在进行速度素质练习的时候, 由于下肢力量 比较薄弱, 使得他们在跑动过程中有劲无法使, 或者跑 动的时候产生无力感。因此, 我们可以采用一些既能兼 顾下肢力量又能锻炼速度练习的游戏。比如通过增加腿 部间歇绑沙袋的接力游戏，进行负重和减负的交替练习。 在提高学生下肢力量的同时, 感受减负后身轻如燕的速 度感。同时加入接力缓解, 能够让学生的注意力集中在 相互配合和竞争中。

\section{3. 耐力素质练习中的体育游戏教学}

大学院校体育课堂中, 衡量耐力素质的一个主要测 试指标就是长跑。长跑项目必须有耐力还要有很好的心 肺功能, 对于学生的意志力有很好的锻炼作用。传统的 长跑教学都是让学生简单机械的在操场上一圈一圈的 跑, 因此学生兴趣索然而且很多体能不好的同学根本不 会参与这个项目 ${ }^{[4]}$ 。因此在针对耐力素质练习的时候充 分考虑到学生对耐力练习的内在抵触情绪。我们需要改 变传统的教学思路, 增加项目之间的贯通。例如最近在 高校比较流行的定向越野项目。我们可以采用团队赛的 形式, 让学生自由选择队员, 并且根据自己的能力相互 配合、协商完成定向任务。耐力好一点的同学可以多跑 一点, 耐力差一点的相对少一点距离。而且不论小组内 部怎么调整每个小组的距离是一样的。在比赛以后根据 时间来评选出优胜代表。这样每个小组为了取得好成绩 都会很好的发挥, 可以提高体能按照每个人的身体素质 情况得到锻炼。为了做好这种耐力项目的游戏要提前做 好准备工作, 如果在户外开展游戏要对场地进行检查, 避免游戏过程中出现危险。

\section{4 柔㓞性素质练习中的体育游戏}

柔韧性素质对掌握运动技术、预防受伤的预感性和 可能性、保持肌肉的弹性和爆发力、维持身体姿态等方
面都具有很重要的意义 ${ }^{[5]}$ 。柔韧性的好坏, 不仅取决于 结构方面的特点，而且也取决于神经系统支配骨骼肌的 机能状态。在教学中通常测试指标有坐位体前屈、纵䢃 叉等。大学身体素质练习中，男生的柔韧性相对于女生 是比较薄弱的, 很多男生在做柔韧性测试的时候数据都 是负值。传统的拉伸柔韧性, 无论男生和女生都很抵触。 因为柔韧性较差, 很难完成。同时由于男女生在同一课 堂, 碍于面子, 很多人就更加不愿意轻易展示自己的韧 带情况。因此, 在柔韧性素质练习环节增加趣味性的游 戏环节更为重要。一方面可以缓解尷尬场面, 一方面也 能减少压力。例如一字接龙游戏。我们把学生按照男女 生比例分成均等的几个小组, 每一组队员排成纵队, 第 一个队员统一从起点开始, 一脚踩线尽自己所能做一字 䢃叉。第二个队员一脚接第一个队员的脚尖一字䢃叉。 依次接龙, 看哪一个队的纵队拉伸距离最长, 长者获胜。 再比如, 我们可以跨步触摸障碍物接力游戏。当然在柔 㓞性游戏练习之前要做好热身和拉伸运动, 在练习过程 中, 要提醒学生时刻注意和感受自身的柔韧性临界点, 防止意外事故发生。

\section{5. 结语}

在未来大学院校的体育课都要融合体育游戏来进 行体育教学, 因为这种教学模式是同学们乐于接受的一 种教学模式, 在教学中既有科学性又有趣味性, 是一种 寓教于乐的教学方式, 由于提高了学生的兴趣, 所以教 学理念也被学生迅速的接受了, 一些体质不好的学生通 过这种教学方式很快的提高了体能, 因此体育游戏和体 育教学相结合的教学方式, 在大学院校的身体素质练习 教学中得到了很好的教学体验。

\section{REFERENCES}

[1] Occupation: Han.J,Tian.L.F,(2012)On how to improve the physical quality and post physical ability of college students, 44

[2] Research on innovation of ice and Snow Sports : Wang.H.Y, (2019)Analysis of innovative application of Sports Game Strategy in track and field teaching in higher vocational colleges, 76-77

[3] Occupation: Gao.J.L,(2019)Analysis of physical quality practice methods of college students in Physical Education,124-125

[4] Contemporary Sports Technology: Wu.Y,(2012) Application of sports game strategy in track and field teaching in higher vocational colleges,171-173

[5] Way of Success: Zhang.R,(2013) Innovative Application of Sports Game Strategy in track and field teaching in higher vocational colleges, 88 